\title{
Editorial
}

\section{The Behaviours of Alloys under Thermo-Mechanical Treatment}

\author{
Maria Cecilia Poletti ${ }^{1,2}$ \\ 1 Institute of Materials Science, Joining and Forming, Graz University of Technology, 8010 Graz, Austria; \\ cecilia.poletti@tugraz.at; Tel.: +43-(316)-873-1676 \\ 2 Christian Doppler Laboratory for Design of High-Performance Alloys by Thermomechanical Processing, \\ 8010 Graz, Austria
}

Citation: Poletti, M.C. The Behaviours of Alloys under Thermo-Mechanical Treatment. Metals 2021, 11, 677. https://doi.org/10.3390/met11050677

Received: 12 April 2021

Accepted: 13 April 2021

Published: 21 April 2021

Publisher's Note: MDPI stays neutral with regard to jurisdictional claims in published maps and institutional affiliations.

Copyright: (C) 2021 by the author. Licensee MDPI, Basel, Switzerland. This article is an open access article distributed under the terms and conditions of the Creative Commons Attribution (CC BY) license (https:// creativecommons.org/licenses/by/ $4.0 /)$.

\section{Introduction and Scope}

The forging of metals is among the oldest working techniques-about 6000 years old. It has been used to produce goods to develop agriculture, housing, medicine, transport and any human activity. Many of our day-to-day products are made of wrought alloys by a complex combination of thermal and thermomechanical treatments. High-quality products are achieved because their microstructure can be tuned. The alloys undergo plastic deformation, recovery, recrystallization, allotropic phase transformation, phase modifications and damage. Within the workpiece, many of these phenomena can occur simultaneously and heterogeneously. The performance of the final products is the result of the shape and the microstructure obtained after thermomechanical treatments. Specifically, structural parts must be resistant to static and dynamic loads, fracture, creep and/or corrosion.

The development of new alloys and new machines raised new challenges. Are we able to design microstructures with optimized processing routes? Are we able to predict materials properties out of the microstructure configuration? Can we achieve the desired properties with less energy input? The scientific community has been working, in the last century, to explain the behaviour of alloys during thermomechanical treatments. Therefore, experimental and modelling tools were developed and used from the atomic to macroscales. This Special Issue contributes to the design of high-performance wrought parts and the prediction of their properties using fundamental research.

\section{Contributions}

In this Special Issue, the lector will find the analysis of the behaviour of materials under thermomechanical treatments in a total of seven publications. The mechanical properties and microstructural modifications of various alloys were characterized and modelled to explain deformation mechanisms and kinetics of phase modifications during thermomechanical processing.

The issue starts with the theoretical work of B. Viernstein and E. Kozeschnik [1]. In this paper, an integrated framework was developed to combine physical formulations for the microstructure evolution during plastic deformation with constitutive creep models. The framework can be used to account for hot deformation at a constant strain rate, creep at constant stress and relaxation.

The second and third contributions deal with the characterization of nickel-based superalloy [2] and titanium alloys [3] under hot deformation, respectively. In the work of B. Zhang et al. [4], a nickel-based superalloy was produced by welding a powder metallurgy superalloy (the rim) with the wrought superalloy (the bore). The hot deformation mechanisms and the flow behaviour of the couples are similar to those of the single alloys, with larger activation energies. The work of F. Warchomicka et al. [3] deals with the characterization of the evolution of the microstructure of Ti64 alloy using in situ synchrotron diffraction during compression and annealing. The authors demonstrated that dynamic recovery happens during hot deformation and that the recrystallization occurs statically during the heat treatments. 
The works of Q.L. Zhao [4], Z. Gao et al. [5] and Y. Qin et al. [6] deal with the processing of aluminium alloys. The first work [4] analyses the effect of the temperature before rolling on the microstructure and mechanical properties of a 6061 aluminium alloy. The rolling was applied simultaneously with the quenching from the solution treatment temperature. The innovative rolling process was compared with traditional techniques. The combination of substructure formation with dynamic precipitation resulted in improved properties. The second work [5] focuses on the friction stir spot processing of an AA6082 aluminium alloy. Mesoscale models were combined with finite element modelling (FEM) simulation and experimental validations. The grain refined within the processed zone due to geometric dynamic recrystallization. In the work of Y. Qin et al. [6], innovative thermo-mechanical processing was applied to an $\mathrm{Al}-\mathrm{Zn}-\mathrm{Mg}$ alloy, resulting in an increment in the yield strength of 100 and $200 \mathrm{MPa}$ with respect to the T6 condition. The compared processes consisted of cold deformation after different heat treatments. The authors demonstrated that the resulting yield strength is higher than the simple sum of precipitation strengthening, strain hardening and grain-refinement strengthening due to the "interlocking" of dislocations and precipitates.

The analysis of the behaviour of an extruded Mg-Gd-Y-Zn alloy containing longperiod stacking ordered (LPSO) fibres during equal channel angular pressing (ECAP) processing was conducted by G. Garcés et al. [7]. The ECAP processing promoted the dynamic recrystallization of the material and, therefore, the grain refinement. Further strengthening of the alloy was achieved with heat treatments.

\section{Conclusions and Outlook}

The contributions in this Special Issue reveal how the modification of the microstructures of alloys can improve the properties of wrought alloys. Physical models are used to explain and predict these modifications. The new techniques for processing metallic materials and alloys will not cover all the spectra of required properties, and thermomechanical processing will remain competitive for specific products. Society requires high-performance materials with low energy consumption during their processing and service. Thermomechanical treatments with optimized processing routes and new materials will give rise to challenging scientific and technological questions that must be answered.

Funding: This Special Issue was carried out in the framework of CD-Laboratory for Design of High-Performance Alloys by Thermomechanical Processing.

Institutional Review Board Statement: Not applicable.

Informed Consent Statement: Not applicable.

Data Availability Statement: Not applicable.

Conflicts of Interest: The authors declare no conflict of interest.

\section{References}

1. Viernstein, B.; Kozeschnik, E. Integrated Physical-Constitutive Computational Framework for Plastic Deformation Modeling. Metals 2020, 10, 869. [CrossRef]

2. Zhang, B.; Liu, X.; Yang, H.; Ning, Y. The Deformation Behavior, Microstructural Mechanism, and Process Optimization of PM/Wrought Dual Superalloys for Manufacturing the Dual-Property Turbine Disc. Metals 2019, 9, 1127. [CrossRef]

3. Warchomicka, F.; Canelo-Yubero, D.; Zehetner, E.; Requena, G.; Stark, A.; Poletti, C. In-Situ Synchrotron X-ray Diffraction of Ti-6Al-4V During Thermomechanical Treatment in the Beta Field. Metals 2019, 9, 862. [CrossRef]

4. Zhao, Q.-L.; Shan, T.-T.; Geng, R.; Zhang, Y.-Y.; He, H.-Y.; Qiu, F.; Jiang, Q.-C. Effect of Preheating Temperature on the Microstructure and Tensile Properties of 6061 Aluminum Alloy Processed by Hot Rolling-Quenching. Metals $2019,9,182$. [CrossRef]

5. Gao, Z.; Feng, J.; Wang, Z.; Niu, J.; Sommitsch, C. Dislocation Density-Based Modeling of Dynamic Recrystallized Microstructure and Process in Friction Stir Spot Welding of AA6082. Metals 2019, 9, 672. [CrossRef] 
6. Qin, Y.; Lin, S.; Jin, S.; Liu, J. Strengthening Al-Zn-Mg Alloys via Ultra-Fine Lamella Structures Containing a High Density of Dislocations and Clusters. Metals 2019, 9, 140. [CrossRef]

7. Garces, G.; Pérez, P.; Barea, R.; Medina, J.; Stark, A.; Schell, N.; Adeva, P. Increase in the Mechanical Strength of Mg-8Gd-3Y-1Zn Alloy Containing Long-Period Stacking Ordered Phases Using Equal Channel Angular Pressing Processing. Metals 2019 , 9, 221. [CrossRef] 